Weissman, A. (1979) Dysfunctional Attitude Scale: A validation study. Dissertation Abstracts International 40. 1389-1390.

*Steve Moorhead, Lecturer in Cognitive Therapy, University Department of Psychiatry, Royal Victoria Infirmary. Newcastle upon Tyne NE1
4LP: and Jan Scott, Head of Division of Psychiatry, University Department of Psychological Medicine, Gartnavel Royal Hospital, Glasgow GL2 OXH

*Correspondence

\title{
Determining whether senior and specialist registrars choose or reject a career in general adult psychiatry
}

\author{
A survey of factors
}

\author{
Mark Davies and Tom Schlich
}

\begin{abstract}
Aims and method Following concerns over recruitment into general adult psychiatry, this study was undertaken to determine which factors influence senior trainees in psychiatry with regard to whether or not they choose a career in general adult psychiatry. The method used was by postal survey of all senior and specialist registrars in the UK.

Results Of those responding, 32.6\% had chosen a career in general adult psychiatry, while $38.9 \%$ had actively rejected such a career. Twenty-six per cent of respondents had chosen another speciality without actively rejecting general adult psychiatry. For those actively rejecting general adult psychiatry, the top three factors cited were poor resources (57.6\%), high workload (43.2\%) and poor working conditions (30.7\%). Clinical implications Through an awareness of why senior trainees reject general adult psychiatry as a possible career, resources can be targeted more specifically in the future at the factors responsible. and thereby improve recruitment into this speciality.
\end{abstract}

Recent reports have highlighted problems with recruitment into general adult psychiatry consultant posts. From 1994 to 1997 the number of vacant posts in general adult psychiatry has risen from 157 (11.1\% of total posts) to 212 (13.2\% of total posts) (Royal College of Psychiatrists, 1997). In addition, many consultants have been retiring early from general adult psychiatry, many for work-related rather than personal reasons (Kendell \& Pearce, 1997). The main source of recruitment into these consultant posts is from senior and specialist registrars in higher psychiatric training. The aim of this study was to determine the factors significant in whether or not senior and specialist registrars choose a career in general adult psychiatry.

\section{The study}

A survey of specialist and senior registrars training in rotations covering all psychiatric specialities in the UK was carried out between November 1997 and May 1998. A list of all scheme organisers for higher psychiatric training was obtained from the Royal College of Psychiatrists. Senior and specialist registrars were contacted through these scheme organisers and asked to complete a questionnaire.

The questionnaire was designed to determine which factors were of relevance in making final career choices. The questionnaire was in two parts; the first part asked trainees their intended career and speciality, for example, consultant in general adult psychiatry. In the second part respondents were asked to indicate which one of three possibilities applied: (a) that they had decided upon a career in general adult psychiatry: (b) that they had actively rejected a career in general adult psychiatry and had chosen another speciality; and (c) that they had always intended to pursue a career in a speciality other than 


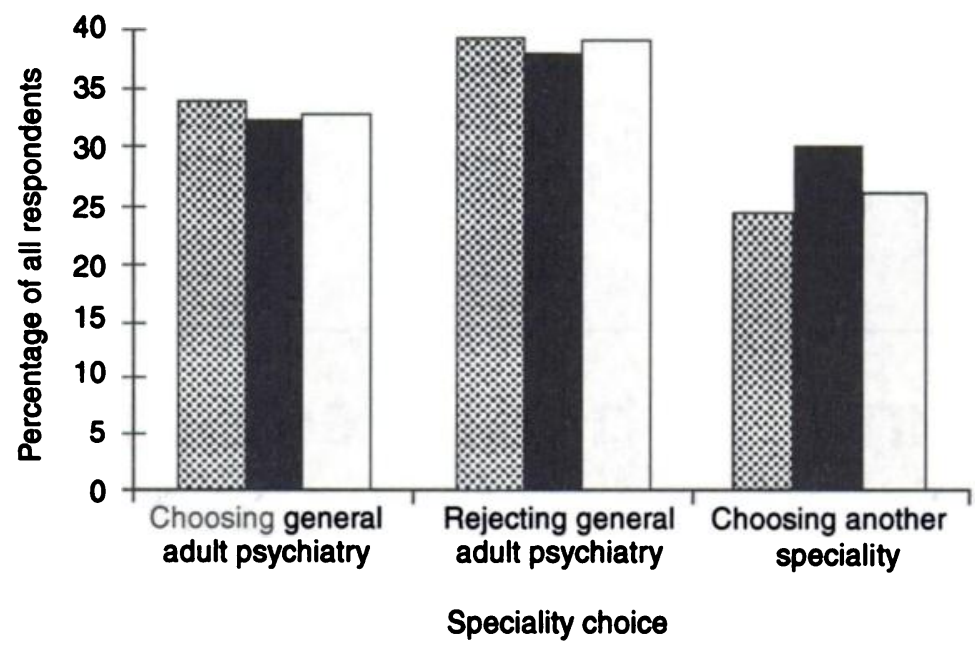

Fig. 1. Percentage of all respondents choosing or rejecting a career in general psychiatry or actively choosing another speciallity. 図, male; $\mathbf{\square}$, female; $\square$, total.

Table 1. Top 10 reasons for choosing a career in general adult psychiatry

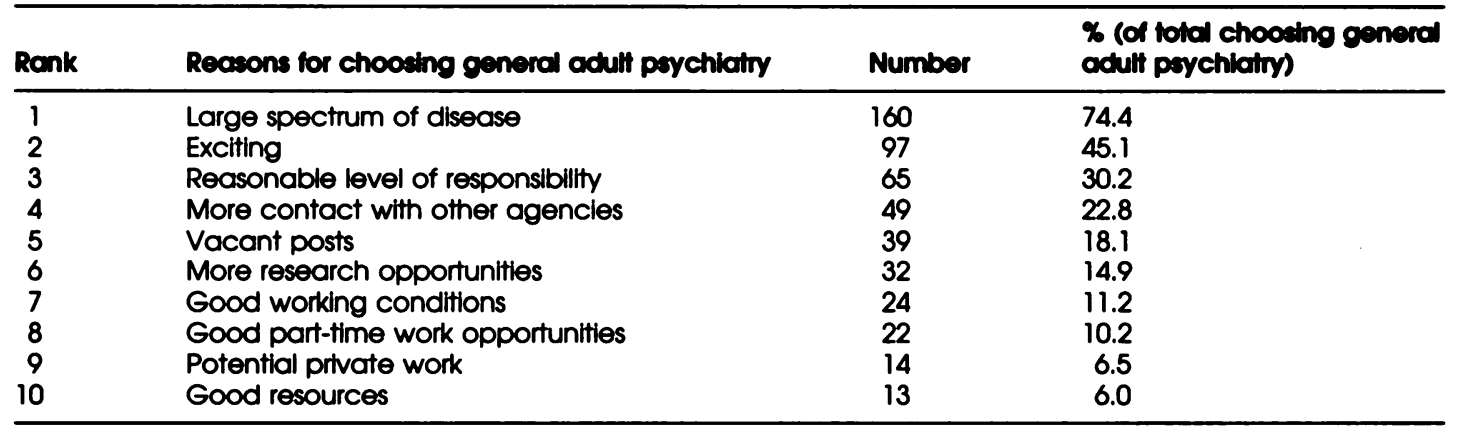

general adult psychiatry. Those trainees for whom category (a) or (b) applied were then asked to specify the factors involved in their career choice. Each respondent was limited to choosing a maximum of four factors of a total of 19 different factors in the questionnaire.

\section{Findings}

A total of 1093 questionnaires were sent of which $660(60.4 \%)$ were returned. Of these respondents 301 (45.6\%) were male, 336 (50.9\%) were female; 23 (3.5\%) did not indicate their gender. Of the total, $595(90.2 \%)$ intended to become consultants, 39 (5.9\%) intended to take up academic teaching posts, two $(0.3 \%)$ wanted to be associate specialists and one $(0.15 \%)$ intended to become a general practitioner; 23 (3.5\%) said they were unsure of their intended status.

The total number choosing a career in general adult psychiatry was $215(32.6 \%)$, while the number actively rejecting a career in general adult psychiatry who consequently chose an alternattve spectality was 257 (38.9\%). The number who had always intended a different speciality and had not actively rejected a career in general adult psychiatry was 172 (26\%). A further $16(2.4 \%)$ were unsure of their final career speciality (see Fig. 1).

The 10 most commonly chosen reasons (out of a total of 19 possible factors) for choosing or rejecting a career in general adult psychiatry are detalled in Table 1 and Table 2 , respectively. As respondents were able to choose up to four of 19 given factors, numbers and percentages in the tables reflect the total scores from the survey.

\section{Comment}

It is encouraging that despite "plummeting morale in adult general psychiatry" (Deahl \& 
Table 2. Top 10 reasons for actively rejecting a career in general adult psychiatry

\begin{tabular}{|c|c|c|c|}
\hline Rank & Reasons for rejecting general octult pesychidiny & Number & $\begin{array}{l}\text { X (of totel actively rejecting } \\
\text { general octulf poschiatry) }\end{array}$ \\
\hline $\begin{array}{l}1 \\
2 \\
3 \\
4 \\
5 \\
6 \\
7 \\
8 \\
9= \\
9=\end{array}$ & $\begin{array}{l}\text { Poor resources } \\
\text { High workload } \\
\text { Poor working conditions } \\
\text { Too much responsibillty } \\
\text { Lack of control over resources } \\
\text { High risk of violence } \\
\text { More govemment directhes } \\
\text { High medla criticism } \\
\text { More inquiries } \\
\text { High risk of Iltigation }\end{array}$ & $\begin{array}{l}148 \\
111 \\
79 \\
61 \\
53 \\
49 \\
46 \\
33 \\
31 \\
31\end{array}$ & $\begin{array}{l}57.6 \\
43.2 \\
30.7 \\
23.8 \\
20.6 \\
19.1 \\
17.9 \\
12.8 \\
12.1 \\
12.1\end{array}$ \\
\hline
\end{tabular}

Turner, 1997) the speciality is still a career choice at consultant level for a significant number of specialist and senior registrars; this seems to be related to factors inherent in the speciality with the large spectrum of disease encountered being cited as the most common favourable reason. Of concern, however, is that the number actively avoiding general psychiatry and seeking an alternative career outnumber those wishing to do general adult psychiatry. Here the three most commonly cited reasons were poor resources and factors consequent to this, namely high workload and poor working conditions. Thus, the speciality may be appealing but the poor resources are not.

If medical students choosing a career in psychiatry do not increase and if specialist and senior registrars avoid a consultant career in general adult psychiatry and choose alternatives, then the problem of filling vacancies is likely to persist. Early retirement of consultants is exacerbating the problem (Kendell \& Pearce, 1997). The vacancies may well represent the tip of an iceberg as trusts are unlikely to be willing to create new posts if they do not believe that these posts can be filled. As a consequence the workload for existing consultants will remain high and these consultants may make their dissatisfaction obvious to their trainees and to medical students. The UK already has a low proportion of psychiatrists per head of population compared with other countries (Muijen, 1993).

General adult psychiatry remains the cornerstone of community care for the mentally ill. The Department of Health has now announced its intention to increase funding for mental health and to review mental health legislation in England (BMU News, 12 December 1998 p. 611). It is vital that this new funding provides real changes to the resources on the ground so that sufficient senior and specialist registrars again become attracted to general adult psychiatry in order to help lift it out of its current doldrums.

\section{Acknowledgements}

Our thanks to Ms Bonnie Burroughs for her invaluable help in administering this project, and to Lilley Industries for supporting the cost of postage and stationery.

\section{References}

DEAHL, M. \& TURNER, T. (1997) General psychlatry in noman's land. Brttish Joumal of Psychtatry, 171, 6-8.

KENDELL, R. E. \& PEARCE, A. (1997) Consultant poychilatrists who retired prematurely in 1995 and 1996. Psychtatric Bullettr, 21, 741-745

MUUEN. M. (1993) The consultant psychiatrist and community care. Psychiatric Bulletin, 17, 513-516.

Royal Colloge of PSYCHIATRISTs (1997) Annual Census of Psychiatric Staffing 1997. Occastonal Paper OP44. London: Royal College of Psychlatrists.

M. Davies, Specialist Registrar, Kings Park Community Hospital, Gloucester Road, Boscombe, Bournemouth, Dorset BH7 6JE; and T. Schlich, Consultant Psychiatrist, Royal South Hants Hospital, Brintons Terrace, Southampton SO14 OYG

*Correspondence 